
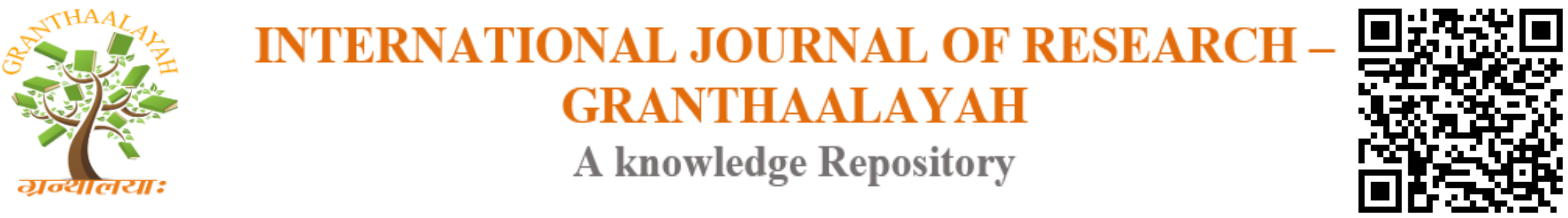

Science

\title{
ANALYSIS OF PROPERTIES OF CONCRETE USING EXPANDED CLAY PEBBLES AS FINE AGGRIGATES
}

\author{
Vishal Gadgihalli ${ }^{* 1}$, MeenaY.R ${ }^{2}$, Abrar Khan ${ }^{3}$, Raghavendra Prasad Havanje Dinakar ${ }^{4}$ \\ ${ }^{* 1}$ UG Student, Department Of Civil Engineering, Jain University, Bangalore, India \\ ${ }^{2}$ Assistant Professor, Department Of Civil Engineering, Jain University, Bangalore, India \\ ${ }^{3}$ UG Students, Department Of Aerospace Engineering, Jain University, Bangalore, India \\ ${ }^{4}$ Research Assistant, Department Of Civil Engineering, Jain University, Bangalore India
}

\begin{abstract}
Aggregate occupies most of the volume of the concrete. It is the stuff that the cement paste coats and binds together. The composition, shape, and size of aggregate all have significant impact on the workability, durability, strength, weight and shrinkage of concrete. In this paper analysis of properties of concrete using clay soil aggregates as course aggregate in concrete, transmitting temperature and temperature reduction time to normal Portland cement in different grade of concrete. Using clay soil aggregate as fine aggregate the transmitting temperature and temperature reduction time will reduces. This gives better results hence we can use clay soil aggregate as course aggregate where temperature of concrete plays an important role. Using expanded clay pebbles as fine aggregates increases the aesthetic appearance, so this can be used in manufacturing ceramics, tiles and crockeries.
\end{abstract}

Keywords: Clay Soil Aggregates; Compressive Strength; Temperature Reduction; Transmitting Temperature and Grade of Concrete.

Cite This Article: Vishal Gadgihalli, MeenaY.R, Abrar Khan, and Raghavendra Prasad Havanje Dinakar. (2017). "ANALYSIS OF PROPERTIES OF CONCRETE USING EXPANDED CLAY PEBBLES AS FINE AGGRIGATES.” International Journal of Research Granthaalayah, 5(11), 333-337. https://doi.org/10.29121/granthaalayah.v5.i11.2017.2360.

\section{Introduction}

Clay soil aggregates are fine-grained natural rock or soil material that combines one or more clay minerals with traces of metal oxides and organic matter. Clay soil aggregates are plastic state due to adhesive character to water content and become hard, brittle and non-plastic upon drying or firing [1][2][3]. The colors of soils content makes clay to appear in various colors from white to dull grey or brown to deep orange-red. Clay soil aggregates are classified into four main groups based on academic sources, kaolinite, montmorillonite steatite, iolite and chlorite. Approximately 30 different types of pure clays based on 'Natural' clay deposits. 
The drawbacks of clay soil aggregates not using as fine aggregate is due to the shrink-swell properties, when wet and retract when dry. This clay soil is also known as expansive soil [4]. Due to the physical and chemical properties of some clays [5] huge swelling occurs when water is absorbed. As these soils dry deep cracks can form on the surface, which then allows water to penetrate to deeper layers of the soil [3].

This change of volume property of clay can cause damage to existing structures, such as cracks in foundations or the walls any structures.

The property of shrink and swell is measured by coefficient of linear extensibility.

The author has experiment the clay soil aggregates as fine aggregates as these aggregates shows adhesive characteristics and good temperature absorbing. Thus using of clay soil aggregates as fine aggregates to experience different results.

\section{Methodology}

Fine Aggregates of clay pebbles were collected and these aggregates are separated through all dust such as leaves, dust and other wastes.

These fine aggregates are allowed to first pass through $10 \mathrm{~mm}$ sieve, as then $4.75 \mathrm{~mm}$ sieve consequently. These fine aggregates are carefully handled so that no other particles must not entering inside, these aggregates then mixed with course aggregates and cement to form concrete powder using proportions, as per IS10262-2009

An empty spaced cube with bottom, size of $10 * 10 * 10 \mathrm{cmcasted}$ using concrete with pebbled clay used fine aggregate concrete and walls of thickness $1 \mathrm{~cm}$ was prepared. Water of $100^{\circ} \mathrm{c}$ was filled in empty cube and the time consumed for reduction of temperature of water to $40^{\circ} \mathrm{c}$ was noted down.

An empty cube casted by using clay pebbled used fine aggregate concrete size $10 * 10 * 10$ was inserted into another larger empty cube casted using plane cement concrete size of $5^{*} 15^{*} 10 \mathrm{~cm}$. $3 \mathrm{~cm}$ sufficient space was left between two cubes was filled with Water of 100 degree centigrade and top side of cube was closed by lid. Water temperature inside the clay cube was noted down after 8 mins for 1, 7, 14, 21, 28 days of similar casted samples. 


\section{Results and Discussions}

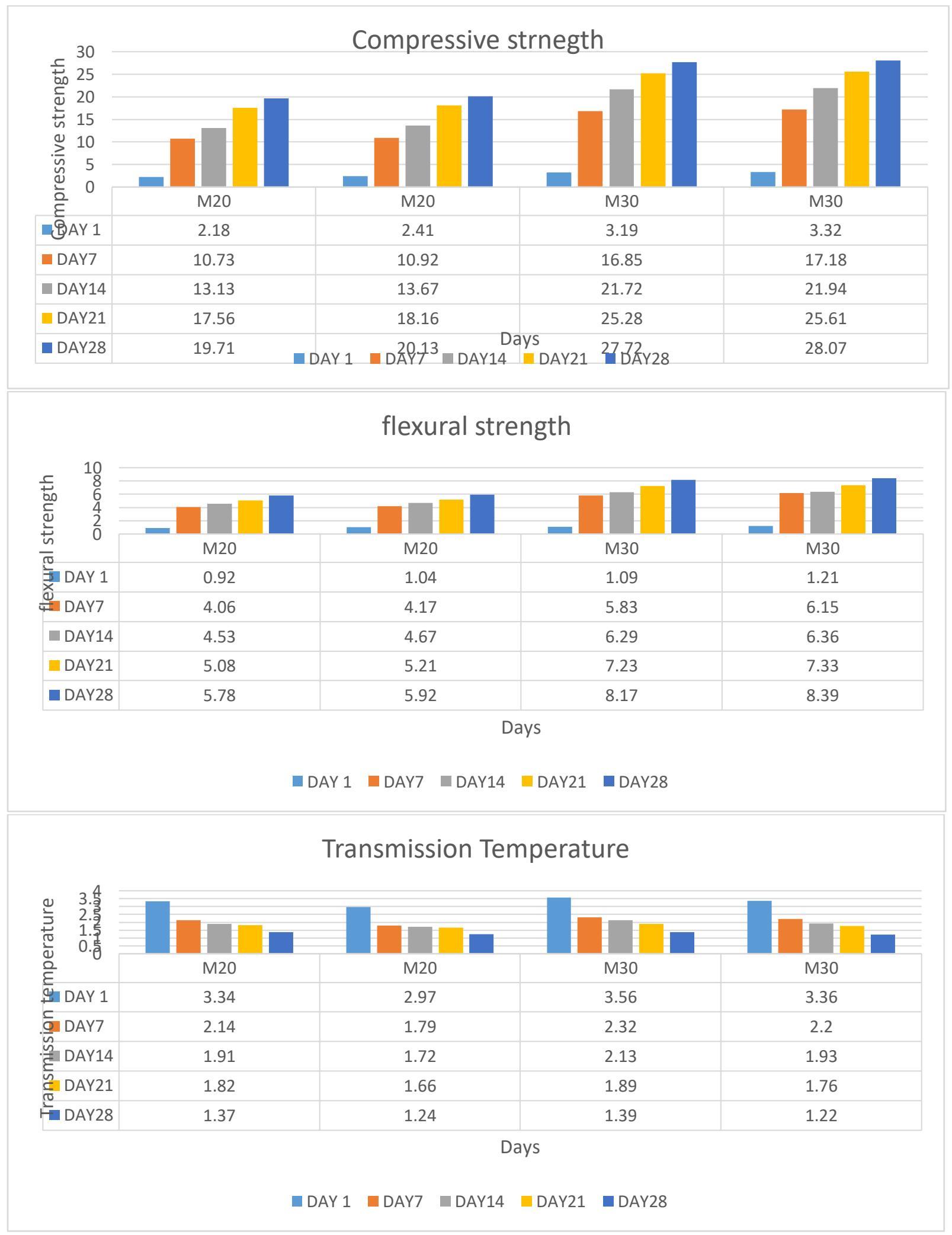




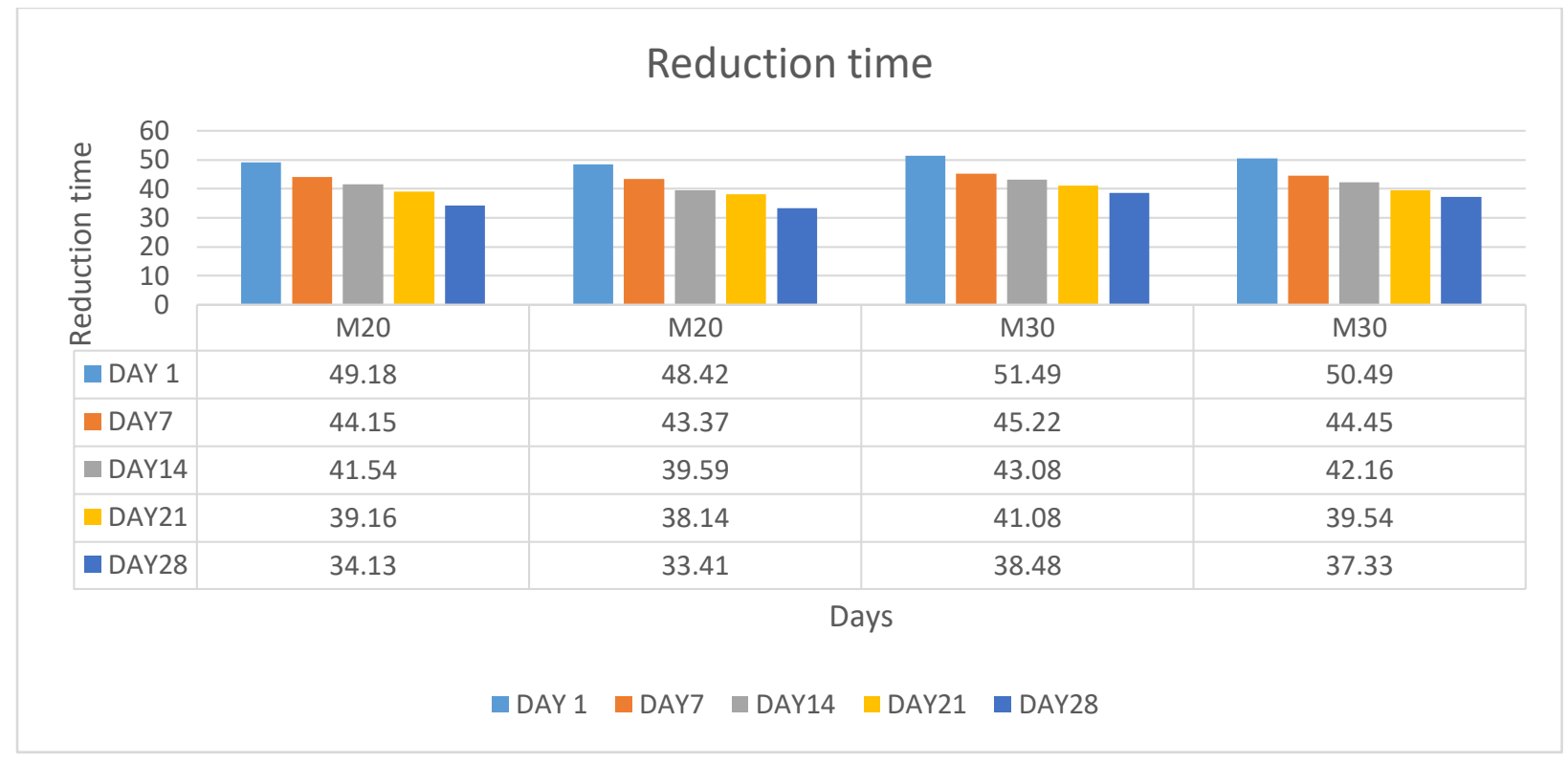

\section{Conclusions \& Recommendations}

From the fig (3) it can be observed the M20 grade and M30 grade concrete with clay soil aggregates concrete transmitted less temperature $1.37 \mathrm{oc}$ and $1.390 \mathrm{c}$ respectively. This clearly states that approximately $10 \%$ of heat transmitting property has decreased. In fig (4) shows, time taken by each sample to reduce its temperature from 100 degree centigrade to 40 degree centigrade. Present study reveals that clay soil aggregate concrete cube takes very less time 33 $\min 41 \mathrm{sec}$ and $37 \mathrm{~min} 33 \mathrm{sec}$ compared to normal course aggregate concrete taking 34 min 13 sec and $38 \mathrm{~min} 48 \mathrm{sec}$ for M20 and M30 grade respectively. That is approximately $1 \mathrm{~min} 30 \mathrm{sec}$ faster. Hence it says the temperature liberating during exothermal reaction may be less in clay soil aggregates cubes.

Although fig [1] and fig [2] shows compressive strength and flexural strength of concrete cubes with clay soil aggregates used as fine aggregate and normal course aggregates cube. The values of results are not considerable because clay aggregates swells and shrinks drastically.

Hence, doing we can't use clay soil aggregates as fine aggregates for building or road construction but, it can be used in manufacture of tiles and crockeries manufactures where temperature holding capacity place a major role.

\section{Acknowledgements}

Special thanks for Goutham Gadgihalli, HitheshNagothu, Megha.R for helping me in completing this work successfully. And I also thank my parents, teachers, friends and all elders who supported me. 


\section{References}

[1] Guggenheim, Stephen; Martin, R.T (1995); "Definition of clay and clay mineral; Journal report of the AIPEA nomenclature and CMS nomenclature committees", clays and clay mineral, 43(2); 255-256, Bid code; 1995CCM...43...255G, doi: 10.1346/CCMN.1995.0430213.

[2] Ehlers, Ernest G. and Blatt, Harvey (1982); 'petrology, igneous, sedimentary and metamorphic' San Francisco; W.H.Freeman and company. ISBN 0-7167-1279-2.

[3] 'Soil properties shrink/ swell-potential/NRC'S Retrieved 2015-11-13.

[4] Nagel, David', soil science for vegetable producers. 'MSU; coordinated Access to the Reaserch and Extension system. 2001-Mississippi state U.6 July 2008:

[5] Moktaci, Masoumeh; Dehghanimosoud, "swell-shrink Behaviour of expansive soil, Damage and control”. Retrieved 3 November 2015.

*Corresponding author.

E-mail address: g.vishal1912@gmail.com 